\title{
ESTUDO DE REMOÇÃO DAS IMPUREZAS PRESENTES NO GLICEROL PROVENIENTE DO BIODIESEL ATRAVÉS DA ADSORÇÃO
}

\author{
V. C. ARABIDIAN ${ }^{1}$, S. F. LÜTKE ${ }^{1}$, N. SILVEIRA Jr ${ }^{1}$, T. R. S. CADAVAL Jr ${ }^{1}$ e L. A. A. \\ PINTO $^{1}$ \\ ${ }^{1}$ Universidade Federal do Rio Grande, Escola de Química e Alimentos \\ E-mail para contato: viarabidian@ hotmail.com
}

\begin{abstract}
RESUMO - A produção de biodiesel gera, como coproduto o glicerol, o qual possui impurezas como pigmentos e íons metálicos. Neste trabalho foram avaliadas as capacidades do carvão ativado comercial e da vermiculita ativada como adsorvente para a remoção de pigmentos do glicerol bruto proveniente da produção de biodiesel. Os adsorventes foram utilizados nas proporções de 0,50 ; 1,00 e $1,50 \%(\mathrm{~m} / \mathrm{m})$, e a temperatura dos experimentos foi de $60^{\circ} \mathrm{C}$. O glicerol bruto foi caracterizado quanto à massa específica, umidade, acidez, sólidos dissolvidos e cor, sendo importante frisar que estas características variam em cada processo. A remoção dos pigmentos foi determinada através da análise no ultravioleta (UV-vis) e a remoção de íons foi determinada através da condutividade da solução. A vermiculita ativada não apresentou capacidade de remover tanto pigmentos quanto íons dissolvidos. O carvão ativado foi eficaz na remoção de pigmentos, entretanto não foi possível detectar a remoção de íons dissolvidos utilizando este adsorvente.
\end{abstract}

\section{INTRODUÇÃO}

Atualmente, a maior parte do glicerol é obtida a partir da produção de biodiesel, na qual ele se encontra como subproduto correspondendo a $10 \%$ em massa de todo biodiesel gerado (Atadashi et al., 2011). Devido ao estímulo para produção de biocombustíveis no Brasil, o biodiesel destaca-se principalmente após a criação da Lei ${ }^{\circ} 13.033 / 2014$, na qual o teor do mesmo no diesel passou de $6 \%$ para $7 \%(\mathrm{~m} / \mathrm{m})$, ocasionando um aumento na produção de seu principal subproduto.

Contudo, o glicerol obtido nesse processo possui diversas impurezas como íons metálicos dissolvidos, provenientes da rota catalítica alcalina, que é a mais utilizada, pois catalisadores como $\mathrm{NaOH}$ e $\mathrm{NaCH}_{3} \mathrm{O}$ são os que apresentam maior atividade (Martin e Frantisek, 2009). O glicerol bruto pode passar por etapas de concentração por evaporadores, e em alguns casos por uma operação de destilação, e ao ser submetido à temperaturas elevadas o mesmo reage formando acroleína, que junto com sabões e resíduos do meio reacional, atribuem cor acentuada ao glicerol. (Adhikari et al., 2008; Slinn et al., 2008) 
Essas impurezas impossibilitam sua aplicação no setor industrial, sendo relevante o desenvolvimento de metodologias adequadas para purificação deste composto a fim de tornar viável sua utilização nas indústrias, principalmente cosmética e farmacêutica (Martin e Frantisek, 2009)

Nesse contexto, a adsorção é uma operação que possibilita o tratamento do glicerol de maneira acessível, a um relativo baixo custo, além de possuir alta eficiência (Cadaval et al, 2013). Assim sendo, o objetivo do trabalho foi comparar dois adsorventes na remoção de pigmentos e íons do glicerol bruto proveniente da produção de biodiesel.

\section{MATERIAL E MÉTODOS}

\subsection{Glicerol}

O glicerol bruto foi adquirido em uma empresa do RS, sendo um coproduto da produção de biodiesel. O mesmo foi armazenado à temperatura ambiente. Os experimentos foram realizados no Laboratório de Tecnologia Industrial, da Escola de Química e Alimentos (EQA), da Universidade Federal do Rio Grande (FURG). O teor de cinzas foi obtido em mufla a $550^{\circ} \mathrm{C}$. A umidade foi determinada em estufa a vácuo com temperatura de $80^{\circ} \mathrm{C}$, sendo a amostra pesada a intervalos regulares até atingir massa constante. A massa específica do glicerol foi feita por picnometria e a acidez determinada por titulação, utilizando solução de $\mathrm{NaOH} 0,1 \mathrm{~N}$ com fenolftaleína como indicador. A cor do glicerol foi determinada em um colorímetro LoviBond (Lovibond Colour Staler Tintometer, model F, Reino Unido), e a remoção de pigmentos foi determinada através de análise no ultravioleta-visível (Shimadzu, Japão). Como controle foi utilizada a glicerina bidestilada (Synth, Brasil).

\subsection{Adsorventes}

Os adsorventes utilizados foram o carvão ativado (Vetec, Brasil), e a vermiculita foi ativada segundo Zhang et al. (2009).

O carvão ativado apresentou as seguintes características diâmetro médio de partícula (Dp) de $68 \pm 6 \mu \mathrm{m}$, área superficial específica (As) de $650 \pm 10 \mathrm{~m}^{2} \mathrm{~g}^{-1}$, esfericidade ( $\varnothing$ ) de $0,75 \pm 0,05$ e massa específica $(\rho)$ de $1100 \pm 10 \mathrm{~kg} \mathrm{~m}^{-3}$. A caracterização da vermiculita ativada será feita se esta se mostrar promissora no trabalho.

A vermiculita foi ativada utilizando ácido clorídrico conforme descrito em Zhang et. al. (2009). Por este método, $25 \mathrm{~g}$ de vermiculita foram misturadas com $800 \mathrm{~mL}$ de solução de $\mathrm{HCl} 2 \mathrm{~mol} / \mathrm{L}$, e a suspenção resultante foi deixada sob agitação por $12 \mathrm{~h}$. Após este período, a suspensão foi filtrada e o sólido foi lavado até que a água de lavagem alcançou pH igual a 7.0. O sólido então passou por uma secagem a $300^{\circ} \mathrm{C}$ por $12 \mathrm{~h}$.

\subsection{Experimentos de Adsorção}

Amostras de $30 \mathrm{~g}$ de glicerol bruto foram aquecidas sob agitação constante (150 rpm) utilizando um agitador magnético com aquecimento. Os experimentos foram realizados à pressão atmosférica e após atingir a temperatura de $60^{\circ} \mathrm{C}$, que foi determinada em teste preliminares como sendo a temperatura mais favorável para adsorção, o adsorvente foi adicionado à amostra. Para avaliar o comportamento do sistema, foram utilizadas diferentes 
concentrações de adsorvente $(0,50 ; 1,00$ e $1,50 \% \mathrm{~m} / \mathrm{m})$, e um tempo de contato entre adsorvente e glicerol de 60 min (condição de equilíbrio). Em seguida, o adsorvente foi isolado do glicerol por filtração a vácuo. Todos experimentos foram realizados em triplicata, e as amostras foram analisadas quanto a cor através do método LoviBond, e a remoção dos pigmentos por absorbância no ultravioleta (UV-vis) a $265 \mathrm{~nm}$. A quantidade de íons dissolvidos foi avaliada através da condutividade elétrica da solução.

A remoção dos pigmentos foi expressa na forma percentual, conforme a Equação 1.

$$
\% R=\frac{\left(A_{0}-A_{e}\right)}{A_{0}} \times 100
$$

onde $\% R$ é a quantidade de pigmentos removida expresso na forma percentual. $A_{0}$ é a absorbância do pigmento na condição inicial do glicerol (adimensional) e $A_{e}$ é absorbância do pigmento após a adsorção (adimensional). A remoção de cor LoviBond foi calculada através da Equação 2 para o amarelo e o vermelho.

$$
\% R_{C}=\frac{\left(I_{0}-I_{e}\right)}{I_{0}} \times 100
$$

onde $\% R_{C}$ é a quantidade de cor LoviBond removida expresso na forma percentual, $I_{0}$ é o índice de cor na condição inicial do glicerol (adimensional) e $I_{e}$ é o índice de cor após a adsorção (adimensional).

Os critérios utilizados neste estudo foram baseados em testes preliminares e dados da literatura (Morais et al., 2001; Ribeiro et al., 2001; Silva et al., 2013) para óleo de pescado, na qual foram desenvolvidos estudos similares.

\section{RESULTADOS E DISCUSSÃO}

O glicerol bruto foi caracterizado quanto ao teor de cinzas, umidade, acidez e cor. A Tabela 1 apresenta os resultados das características físico-químicas do glicerol bruto.

Tabela 1 - Características físico-químicas do glicerol bruto

\begin{tabular}{|c|c|c|}
\cline { 2 - 3 } \multicolumn{1}{c|}{} & Glicerol bruto & $\begin{array}{c}\text { Glicerina bi- } \\
\text { destilada }\end{array}$ \\
\hline Umidade (\%) & $13,48 \pm 0,24$ & $<0,50$ \\
\hline Cinzas (\%) & $5,68 \pm 0,02$ & $<0,04$ \\
\hline Acidez (\%) & nd & nd \\
\hline Sabões (\%) & nd & nd \\
\hline $\begin{array}{c}\text { Índice de cor amarela } \\
\text { (adimensional) }\end{array}$ & $15,0 \pm 0,3$ & nd \\
\hline $\begin{array}{c}\text { Índice de cor vermelha } \\
\text { (adimensional) }\end{array}$ & $7,5 \pm 0,2$ & nd \\
\hline
\end{tabular}

nd- não detectado. (\%)- percentagem em massa..

A Tabela 1 apresenta as características do glicerol bruto (subproduto do biodiesel) e também da glicerina bidestilada utilizada como referência. As características do glicerol bruto 


\section{Congresso Brasileiro de Engenharia Química em Iniciação Científica UFSCar - São Carlos - SP 16 a 19 de Julho de 2017}

podem variar de acordo com o processo principalmente no que diz respeito ao teor de sabões e acidez. As cinzas são provenientes principalmente do catalisador utilizado, mas também dos ácidos e bases utilizados nas etapas de remoção dos sabões do glicerol. Como pode ser observado na Tabela 1, o glicerol bruto possui uma qualidade inferior a glicerina bidestilada presente no mercado. $\mathrm{O}$ glicerol bruto apresentou pureza inferior a $85 \%$, ao passo que a glicerina industrial, usada como referência, apresentou pureza superior 99,5\%. Estas características colocam este material numa condição bastante inferior em relação a qualidade da glicerina presente no mercado evidenciando a necessidade de sua purificação. As análises realizadas após os experimentos de adsorção mostraram que os teores de umidade, cinzas, acidez e sabões no glicerol bruto não se alteraram.

A Tabela 2 apresenta os percentuais de remoção de cor e pigmentos do glicerol utilizando o carvão ativado.

Tabela 2 - Percentual de cor e pigmentos removidos do glicerol bruto pelo carvão ativado

\begin{tabular}{|c|c|c|c|}
\hline \multirow{2}{*}{ Quantidade de carvão (\%) } & \multicolumn{3}{|c|}{ Remoção } \\
\cline { 2 - 4 } & $\% R$ & $\% R_{\text {C(amarelo })}$ & $\% R_{C(\text { vermelho })}$ \\
\hline $\mathbf{0 , 5}$ & $42,7 \pm 0,5$ & $75,4 \pm 1,2$ & $82,7 \pm 1,8$ \\
\hline $\mathbf{1 , 0}$ & $67,5 \pm 0,3$ & $83,4 \pm 0,7$ & $88,0 \pm 0,4$ \\
\hline $\mathbf{1 , 5}$ & $79,6 \pm 0,8$ & $95,8 \pm 2,1$ & $96,1 \pm 1,1$ \\
\hline
\end{tabular}

Como pode ser visto na Tabela 2, as remoções das cores amarela e vermelha foram maiores do que a remoção total de pigmentos. Esta diferença se dá pelo fato do método LoviBond ser específico para compostos que geram coloração amarela e vermelha no meio fluido, ao passo que a avaliação no UV-vis identifica além destes compostos, outros que também absorvam a radiação a $265 \mathrm{~nm}$. Neste ponto é importante mencionar que a glicerina padrão não absorve radiação na região do UV-vis e o glicerol bruto apresentou uma única região de absorção, com um máximo em $265 \mathrm{~nm}$. Isso evidencia a presença de impurezas no glicerol com natureza diferente daquelas que causam os tons amarelo e vermelho.

Ao longo dos experimentos foi observado que o carvão ativado não removeu íons dissolvidos. A razão disso acontecer pode ser explicado pela completa ocupação dos poros pelos pigmentos gerando um efeito de matriz que impossibilitou sua remoção.

A utilização da vermiculita ativada se deu pois testes preliminares mostraram que este material apresenta capacidade de remover íons devido apresentar características, após ativação, semelhantes às resinas catiônicas. Entretanto, quando este material foi colocado em contato com o glicerol bruto, não foi verificado a remoção tanto de íons quanto de pigmentos. Novamente a complexidade da matriz glicerol pode ser responsável por impedir a interação entre adsorvente e adsorbato para este sistema.

\section{CONCLUSÃO}


O glicerol analisado, por apresentar baixo teor de pureza, não apresentou resultados satisfatórios para sua utilização direta em processo de adsorção. De acordo com os experimentos de adsorção, a vermiculita demonstrou pouca capacidade de adsorver os pigmentos do glicerol bruto, visto que os valores de absorbância e índice de cor praticamente não foram alterados em comparação ao glicerol controle. Ficou evidenciado pela diferença de resultados de LoviBond e UV-vis que o glicerol bruto apresenta contaminantes com natureza diferente daqueles que causam as cores amarela e vermelha. Pelos resultados obtidos por condutividade elétrica, ficou evidenciado que tanto a vermiculita ativada quanto o carvão ativado não foram eficazes na remoção de íons dissolvidos presentes pois o efeito de matriz reduziu a capacidade de interação entre adsorvente e adsorbato. $\mathrm{O}$ carvão ativado mostrou bom desempenho na remoção dos pigmentos do glicerol, reduzindo seus índices de cor em mais de $96 \%$ e pigmentos totais em mais de $79 \%$.

\section{REFERÊNCIAS}

ADHIKARI S.; FERNANDO S. D.; HARYANTO A. Hydrogen production from glycerin by steam reforming over nickel catalysts. Renew. Energy, v. 33 p. 1097-1100, 2008.

ATADASHI I. M.; AROUA M. K.; ABDUL AZIZ A. Biodiesel separation and purification: A review. Renew. Energy, v. 36 p. 437-443, 2011.

CADAVAL, T. R. S.; CAMARA, A. S.; DOTTO, G. L.; PINTO, L. A. A. Adsorption of Cr (VI) by chitosan with different deacetylation degrees. Desalination and Water Treatment, v. 51, p. 7690-7699, 2013.

MARTIN, F.; FRANTISEK, S., 44th International Petroleum Conference, Bratislava, Slovak Republic, p. 21-22, 2009.

MORAIS, M. M.; PINTO, L. A. A.; ORTIZ, S. C. A.; CREXI, V. T.; SILVA, R. L.; SILVA, J. D. Estudo do processo de refino do óleo de pescado. Rev. Inst. Adolfo Lutz., v. 60, p. 23-33, 2001.

RIBEIRO, M. H. L.; LOURENÇO, P. A. S.; MONTEIRO J. P.; FERREIRA-DIAS, S. Kinetics of selective adsorption of impurities from a crude vegetable oil in hexane to activated earths and carbons. Euro. Food Res. Tech., 213, p. 132-138, 2001.

SILVA, S. M.; SAMPAIO, K. A.; CERIANI, R.; VERHÉ, R.; STEVENS, C.; DE GREYT, W.; MEIRELLES, A. J. A. Adsorption of carotenes and phosphorus from palm oil onto acid activated bleaching earth: Equilibrium, kinetics and thermodynamics. J. Food Eng., v. 118, p. 341-349, 2013.

SLINN, M.; KENDALL, K.; MALLON, C.; ANDREWS, J. Steam reforming of biodiesel byproduct to make renewable hydrogen. Bioresource Technol., v. 99, p. 5851-5858, 2008.

ZHANG, K.; Xu, J.; WANG, K. Y.; CHENG, L.; WANG, J.; LIU, B. Preparation and characterization of chitosan nanocomposites with vermiculite of different modification. Polym. Degrad. Stab., v. 94, p. 2121-2127, 2009. 